\title{
Road Service Performance Based On Integrated Road Design Consistency (IC) Along Federal Road F0023
}

\author{
Zaffan Farhana Zainal ${ }^{1}$, Joewono Prasetijo ${ }^{1, *}$, and Wan Zahidah Musa ${ }^{1}$ \\ ${ }^{1}$ Smart Driving Research Center (SDRC), Faculty Civil and Environmental Engineering, Universiti \\ Tun Hussein Onn Malaysia 86400 Parit Raja, Johor
}

\begin{abstract}
Road accidents are one of the world's largest public health and injury prevention problems. In Malaysia, the west coast area of Malaysia been stated as the highest motorcycle fatalities and road accidents are one of the factors that cause of death and injuries in this country. The most common fatal accident is between a motorcycle and passenger car.The most of the fatal accidents happened on Federal roads with 44 fatal accidents reported, which is equal to $29 \%$. Lacks of road geometric designs consistency where the drivers make mistakes errors due to the road geometric features causes the accident kept rising in Malaysia. Hence, models are based on operating speed to calculate design consistency of road. The profiles were obtained by continuous speed profile using GPS data. The continuous operating speed profile models were plotted based on operating speed model ( $85^{\text {th }}$ percentile). The study was conduct at F0023 from $\mathrm{km} 16$ until $\mathrm{km} \mathrm{20}$. The purpose of design consistency is to know the relationship between the operating speed and elements of geometric design on the road. As a result, the integrated design consistency motorcycle and cars along a segment at F0023, the threshold shows poor design quality for motorcycles and cars.
\end{abstract}

\section{Introduction}

Road accidents are one of the world's largest public health and injury prevention problems. About one million people are killed, three millions are severely disabled for life and thirty millions are injured in road accident according to WHO. In Asian, about 40000 people are killed on the roads annually. Malaysia is one of the developing countries that facing road accidents in Asian and road accidents are one of the factors that cause of death and injuries in this country. In Malaysia, the west coast area of Malaysia been stated as the highest motorcycle fatalities due to the highest number of registered motorcycles and population. Johor was ranked the highest with 27 deaths recorded followed by Selangor (23) and Perak (22). In 2010, the federal government estimated that the number of deaths on motorcycles was 30 times the number of death in cars, per miles travels [1]. The most common fatal accident is between a motorcycle and passenger car. Generally fatal accidents happened on

* Corresponding author: joewono@uthm.edu.my 
Federal roads with 44 fatal accidents reported, which is equal to $29 \%$. Most of the road accidents were attributed to motorcyclists with 92 cases reported, which is equivalent to $61 \%$ of the 150 accidents recorded. According to [2], in early investigation shows that motorcycle accidents are 17 times more dangerous than driving a passenger car.

Accidents usually result from a combination between 4 elements; the driver, the road, the vehicle and the environment [3]. Previous study stated the causes of road accident are faulty vehicles, uneven roads, careless/reckless driving, speeding, drunk driving, inadequate sleep, alcohol and many more. [4] Accidents keep rising in Malaysia, because lacks of road geometric designs consistency where the drivers make mistakes errors due to the road geometric features. If the consistency are poor, the potential for accident happen are highest $[5,6]$.

\section{Design consistency estimation}

Most previous study have developed model of consistency but are less known. One of pervious study have put forth a new model of consistency based on data through continuous speed profile and relate the speed profile with the geometric variables of the road segment and with accident statistics for the segment [7]. Design consistency are defines as the relationship between the geometric characteristics of a highway with the conditions the driver expects when drive. Models are based on operating speed to calculate design consistency of road. Operating speed are defined as the speed selected by the drivers when no restricted by other users or speed under free flow conditions and normally represented by the $85^{\text {th }}$ percentile speed, $V_{85}$. The operating speed profile were developed by of two types of operating speed models; one for horizontal curves and other for tangents. The profiles were obtained by considering continuous speed profile using GPS devices and continuous speed profiles are used to determine the global speed variation along a road segment and determining a single consistency value for the whole road segment.

According [8] purposed new method to check design consistency. Parameters for this model are the bounded area between the profile and the average speed along a two-lane highway segment. As a design consistency increased, crash rates will shown to decrease significantly. The corresponding equations are

$$
R_{a}=\frac{\left(\sum a_{i}\right)}{L}
$$

Where; $R_{a}$ is relative area $(\mathrm{m} / \mathrm{sec})$ measure consistency, $\sum a_{i}$ is sum of $\mathrm{i}$ areas bounded between the speed profile and the average operating speed $\left(\mathrm{m}^{2} / \mathrm{sec}\right), \mathrm{L}$ is entire segment length $(\mathrm{m})$.

$$
\sigma=\left\{\frac{\left(V_{j}-V_{\text {avg }}\right.}{n}\right\}^{0.5}
$$

Where; $\Sigma$ is standard deviation of operating speeds $(\mathrm{km} / \mathrm{h}), V_{j}$ is operating speed along the $\mathrm{j}^{\text {th }}$ geometric element (tangent/curve) $(\mathrm{km} / \mathrm{h}), V_{\text {avg }}$ is average weighted (by length) operating speed along a segment $(\mathrm{km} / \mathrm{h}), \mathrm{n}$ is number of geometric elements along a segment $(\mathrm{km} / \mathrm{h})$.

$$
V_{\text {avg }}=\frac{\sum V_{i} L_{i}}{\sum L_{i}}
$$

Where; $V_{\text {avg }}$ is average weighted (by length) operating speed along a highway segment $(\mathrm{km} / \mathrm{h}), V_{i}$ is operating speed $(\mathrm{km} / \mathrm{h}), L_{i}$ is length of segment $(\mathrm{km})$. The model of consistency $(\mathrm{C})$ and the model integrated design consistency is [8]: 


$$
C=2.808 \cdot \exp ^{\left(-0.278 . R_{a} \cdot \sigma\right)}
$$

Where; $\mathrm{C}$ is basic consistency of a highway segment, $R_{a}$ is normalized area bounded by the average speed profile of cars/motorcycle and the average operating speed $(\mathrm{m} / \mathrm{sec}), \sigma$ is standard deviation of cars speeds $(\mathrm{m} / \mathrm{sec})$.

$$
C=2.808 . \exp ^{\left(-0.278 . R_{a} \cdot \sigma\right)}
$$

Where; IC is integrated consistency of road sections, $R_{a}$ is normalized bounded area by speed profile of cars /motorcycle $(\mathrm{m} / \mathrm{sec}), \sigma$ is standard deviation of car speeds/ motorcycle, ACT is normalized bounded area between the speed profile of cars and motorcycle $(\mathrm{m} / \mathrm{sec})$. To determination threshold for design consistency proposed by [8] is:

Table 1. Design-consistency quality

\begin{tabular}{|c|c|c|}
\hline \multicolumn{3}{|c|}{ Design-consistency quality } \\
$C=2.808 . \exp ^{(-0.278 . R a . \sigma)}$ \\
\hline Good & Acceptable & Poor \\
\hline $\mathrm{C}>2(\mathrm{~m} / \mathrm{s})$ & $1<\mathrm{C} \leq 2(\mathrm{~m} / \mathrm{s})$ & $\mathrm{C} \leq 1(\mathrm{~m} / \mathrm{s})$ \\
\hline
\end{tabular}

\section{Research methodology}

In this study, continuous speed profile was used rather than collecting using spot speeds. GPS DG-200 was attached with the vehicle to record data along a segment. Continuous speed data was collected at the study site in direction of traffic flow. The purpose of the study is to estimate value of index the integrated road design consistency (IC) of motorcycles and cars at F0023 from $\mathrm{km} 16$ to $\mathrm{km} 20$.

\subsection{Site collection}

The data was collected through the test driver with the same vehicle for motorcycle and car. The study site was selected along km16 until km20 at F0023, Jalan Muar - Segamat, Johor. Fig. 1 shows location $\mathrm{km} 16$ - km20 (f0023).

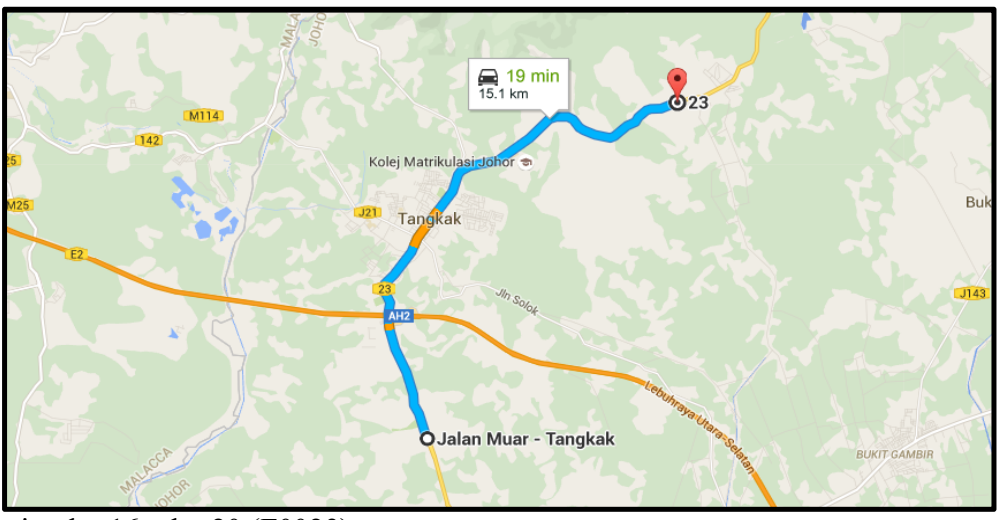

Fig. 1. Location km16 - km20 (F0023)

\subsection{Primary data collection}

Speed data in this study known as a primary data collection. Many years, a GPS technology has been used to collect traffic data for transportation studies. By previous studies, most of 
them using automated traffic counters or radar speed gun measurement to measure speed along the segment [9].Therefore, the continuous speed profile data was using new method analysis to develop road design consistency profile of motorcycle and cars by using global positioning system (GPS). By using GPS, the continuous speed profile data was using new method analysis to develop road design consistency profile of motorcycle and cars and determined value of index the integrated road design consistency (IC). 100 test drivers and riders were instructed to drivers and riders along the selected segment by using the same vehicle and GPS (DG- 200) was placed into moving vehicles; cars and motorcycles. To perform data collection (speed data), only two persons, a driver and a GPS recorder were needed. Speed data from signalized intersection been remove about $300 \mathrm{~m}$ to avoid the effect of traffic control devices on vehicle speeds [10]. Fig. 2 shows GPS DG-200 that be used in this study.

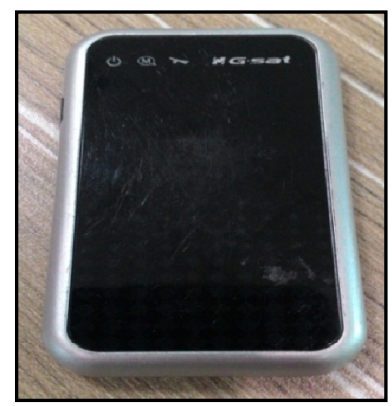

Fig. 2. GPS DG-200

\subsection{Secondary data collection}

Accident data, traffic data and road features are been included as secondary data collection. Accident data collection was collected from data police that includes accident type, location and number of vehicles involving. Traffic data collection includes average annual daily traffic (AADT). Road Features include roads and road characteristics such as length of tangent, length of curve, shoulder width, lane width and access point. The data was collected from authorities or site visit

\section{Results and discussion}

By using statistical software (Minitab), analysis was carried out to develop operating speed model. ACAD Software analysis was using to developed design consistency model.

\subsection{Development operating speed model tangent and curve $\left(85^{\text {th }}\right.$ percentile)}

Profile was plotted based using continuous speed data obtained through GPS DG-200. The models are developed based on the new method of speed profiles analysis. Model prediction of $85^{\text {th }}$ percentile speed for tangent and curve are using linear regression method to developed prediction operating speed model for motorcycles and cars.

- Motorcycles

$$
\begin{array}{ll}
V_{85 t}=61.2+0.41 L_{t}+11.5 S W+0.55 A P & R^{2}=0.43 \\
V_{85 c}=66.0+5.7 L_{c}+6.8 S W+0.43 A P & R^{2}=0.34
\end{array}
$$


- Cars

$$
\begin{array}{ll}
V_{85 t}=40.5+6.46 L_{t}+28.9 S W-1.41 A P & R^{2}=0.94 \\
V_{85 c}=74.6-34.8 L_{c}-9.8 S W+6.48 A P & R^{2}=0.88
\end{array}
$$

Where; $V_{85 t}=$ Operating speed of tangent, $V_{85 c}=$ operating speed of curve, $L_{t}=$ length of tangent, $L_{c}=$ length of curve, $\mathrm{SW}=$ shoulder width, $\mathrm{AP}=$ access point

\subsection{Development design consistency}

The continuous operating speed profile models were plotted based on operating speed model $\left(85^{\text {th }}\right.$ percentile). To developed road design consistency model, ACAD software was used to developed road design consistency model. Plots of operating speed model profile (85th percentile) along the length are called as speed profile for this study. The consistency was calculated for each segment from the speed profile. Fig. 3 shows speed profile F0023 of motorcycles at km21 - km25. Fig. 4 shows speed profile F0023 of cars at km21 - km 25.

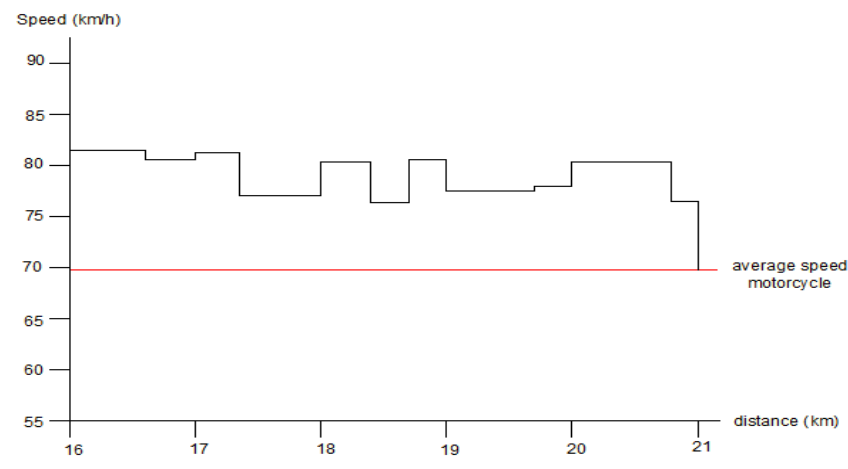

Fig 3. Speed profile F0023 of motorcycles (KM16 - KM20)

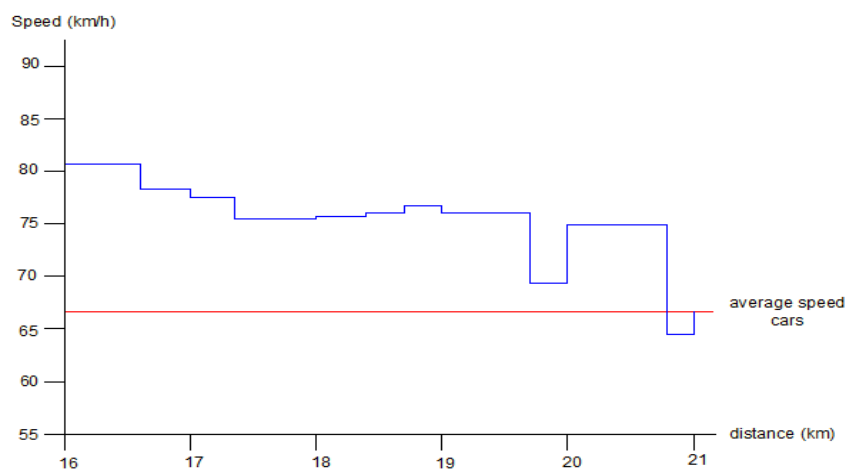

Fig 4. Speed profile F0023 of cars (KM16 - KM20)

The consistency index was estimated based on speed profiles. To estimate consistency index of eq. (4) two parameters were considered. First the value of standard deviation, $\sigma$ was obtained using the operating speed. Second the bounded area between the profile and 
the average speed. Table 2 shows design consistency motorcycles at km16 - km20 per km. Table 3 shows design consistency cars at $\mathrm{km} 16$ - km20 per $\mathrm{km}$. The design consistency model for motorcycle and cars shows the threshold of design-consistency quality is poor design. This is based on road features conditions in this area for motorcycles and cars.

Table 2. Design consistency motorcycle (KM16-KM20) per km

\begin{tabular}{|c|c|c|}
\hline KM & Design Consistency & Threshold \\
\hline 16 & 0.16 & poor \\
\hline 17 & 0.30 & poor \\
\hline 18 & 0.25 & poor \\
\hline 19 & 0.38 & poor \\
\hline 20 & 0.23 & poor \\
\hline
\end{tabular}

Table 3. Design consistency cars (KM16-KM20) per km

\begin{tabular}{|c|c|c|}
\hline KM & Design Consistency & Threshold \\
\hline 16 & 0.11 & poor \\
\hline 17 & 0.27 & poor \\
\hline 18 & 0.28 & poor \\
\hline 19 & 0.46 & poor \\
\hline 20 & 0.51 & poor \\
\hline
\end{tabular}

\subsection{Integrated design consistency model}

The model shows the integrated design consistency model between speed profile of cars and motorcycle. Fig. 5 shows speed profile F0023 between motorcycles and cars at $\mathrm{km} 16-$ $\mathrm{km} 20$. The integrated design consistency between the speed profiles motorcycles and cars can be determined through normalized bounded area between the speed profile of cars and motorcycle. Table 4 shows integrated design consistency between motorcycles and cars at $\mathrm{km} 16-\mathrm{km} 20$ per km.

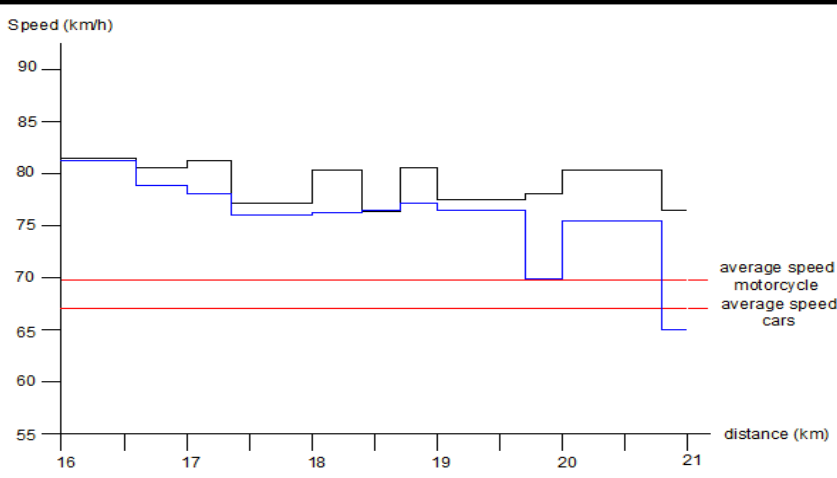

Fig 5. Speed profile F0023 of motorcycles and cars (KM16 - KM20)

The integrated design consistency motorcycle and cars along a segment, the threshold shows poor design for both type vehicles. According to the data police statistics for 5 years $(2010-2014)$ and based on APW shows km16 is a high accident area. The road design at 
$\mathrm{km} 16$ gave influence of the road driving in this area based on threshold design consistency. Other than, for whole road km 16 until km 20 at F0023 has poor design. There may be several factors that affect the design such as access points that located in this area. F0023 $(\mathrm{km} 16$ - $\mathrm{km} 20)$ the area has no median, the main road of the residents in this area, industrial area and estates area along the segment. It shows, accident occur are not based on speed fault but the factor of surrounding area and driver behavior.

Table 4. Integrated Design consistency motorcycles and cars (KM16 - KM20) per km

\begin{tabular}{|c|c|c|c|}
\hline KM & Integrated Design Consistency & Threshold & APW \\
\hline 16 & 0.11 & poor & 35 \\
\hline 17 & 0.27 & poor & 15.4 \\
\hline 18 & 0.27 & poor & 14.2 \\
\hline 19 & 0.45 & poor & 16.4 \\
\hline 20 & 0.48 & poor & 6.8 \\
\hline
\end{tabular}

\section{Conclusions}

Most of the model developed using the spot speed data from equipment such as radar gun. GPS data loggers were used to develop the continuous speed profiles. Furthermore, design consistency profile of motorcycles - cars were developed by $85^{\text {th }}$ percentile operating speed model of motorcycle and cars. In Malaysia, the design consistency models have not been used to evaluate geometric design at rural road, previously. The purpose of design consistency is to know the relationship between the operating speed and elements of geometric design on the road.

Design consistency was influenced the driver to drive in a safe condition. The design consistency model was developed based on two independent; the bounded area between the profile and the average speed and the standard deviation of speeds with results in Integrated Design Consistency (IC). The integrated design consistency models were based on normalized bounded area between the speed profile of cars and motorcycle and design consistency.

It can be concluded from the study that integrated design consistency (IC) motorcycles cars shows that the poor design consistency with the higher potential accident occurs. Even though, the accident was not high according to APW, but the road design shows poor design consistency along a segment.

The authors would like to thanks to the Universiti Tun Hussein Onn Malaysia in funding this study under the Geran Kontrak UTHM Vot. U395. Further thanks are also for Smart Driving Research Center (SDRC), Faculty of Civil and Environmental Engineering, Universiti Tun Hussein Onn Malaysia (UTHM) for support and providing facilities to accomplish the study.

\section{References}

[1] D.G. Lee, Motorcycle vs Car Accident Statistics, (2012). Reached at September 5, 2016, from http://motorcycleaccidentlawyerpa.com/motorcycle-vs-car-accident-statistics/

[2] U. Radin, Updates of road safety status in Malaysia, IATSS Research, 29, 78-80 (2005)

[3] H. Farah, A. Polus, M. Cohen, Multivariate analyses for infrastructure-based crashprediction models for rural highways, Road and Transport Research: A J. of Australian and New Zealand Research and Practice, 16(4), 26 (2007) 
[4] A. Kareem, Review of global menace of road accidents with special reference to Malaysia-a social perspective, Malaysian Journal of Medical Sciences 10(2), (2003)

[5] R. Lamm, B. Psarianos, T. Mailaender, Highway design and traffic safety engineering handbook, New York, (1999)

[6] J. De Oña, L. Garach, Accidents prediction model based on speed reduction on Spanish two-lane rural highways, Procedia-Social and Behavioral Sciences, 53, 1010-1018 (2012)

[7] L.G. Morcillo, F.J.C. Poyo, M.P. Fernández, J. de Oña, Measurement of road consistency on two-lane rural highways in Granada (Spain), Procedia-Social and Behavioral Sciences, 162, 237-242 (2014)

[8] C. Mattar-Habib, A. Polus, H. Farah, Further evaluation of the relationship between enhanced consistency model and safety of two-lane rural roads in Israel and Germany, EJTIR, 4(8), 320-332 (2008)

[9] J. Prasetijo, Z.F. Zainal, W.Z. Musa, Speed profile based on design consistency, Proc. Int. Conf. on Engineering of Tarumanagara, Jakarta, Indonesia, (2015)

[10]J. Prasetijo, Z.F. Zainal, Development of continuous speed profile using GPS at Johor Federal Roads F0050, MATEC Web of Conferences, 47, (2016) 